

\title{
Complex Susceptibility Measurement Using Multi-frequency Slingram EMI Instrument
}

François Xavier Simon, Alain Tabbagh, Julien Thiesson, J.C. Donati, A. Sarris

\section{To cite this version:}

François Xavier Simon, Alain Tabbagh, Julien Thiesson, J.C. Donati, A. Sarris. Complex Susceptibility Measurement Using Multi-frequency Slingram EMI Instrument. Near Surface Geoscience 2014: 20th European Meeting of Environmental and Engineering Geophysics, Sep 2014, ATHENES, Greece. hal-01147331

\section{HAL Id: hal-01147331 \\ https://hal.sorbonne-universite.fr/hal-01147331}

Submitted on 30 Apr 2015

HAL is a multi-disciplinary open access archive for the deposit and dissemination of scientific research documents, whether they are published or not. The documents may come from teaching and research institutions in France or abroad, or from public or private research centers.
L'archive ouverte pluridisciplinaire HAL, est destinée au dépôt et à la diffusion de documents scientifiques de niveau recherche, publiés ou non, émanant des établissements d'enseignement et de recherche français ou étrangers, des laboratoires publics ou privés. 
We PA1 04

Complex Susceptibility Measurement Using Multifrequency Slingram EMI Instrument

F.-X. Simon* (IMS FORTH), A. Tabbagh (UMR Methis), J. Thiesson (UMR Methis), J.C. Donati (GeoSat ReSeArch, IMS FORTH) \& A. Sarris (GeoSat ReSeArch, IMS FORTH)

\section{SUMMARY}

Complex magnetic susceptibility is a well-known property both theoretically and experimentally. To achieve this measurement, different ways have been tested, like TDEM or multi-frequential measurement on soil sample. In this study we carry out the measurements by the use of a multi-frequential EMI

Slingram instrument to collect data quickly and in-situ. The use of multi-frequency data is also a way to correct effects of the conductivity on the in-phase component and effects of the magnetic susceptibility on the quadrature component of the raw signal. 


\section{Introduction}

The use of EMI devices for soil mapping is well-known, especially for the measurement of electrical conductivity in environmental or archaeological studies. To neglect displacement currents, the used frequencies are lower than $100 \mathrm{kHz}$. According to the low induction number (LIN) approximation, conductivity is in quadrature out of phase from the transmitter moment which allows the measurement of the magnetic susceptibility on the in-phase part of the signal. Under this approximation also the depth of investigation only depends on instrument geometry, meaning the choice of coils spacing and orientations.

Although EM instruments are built to avoid any conductivity dependence in the in-phase part signal, in practice the measurement could be more complex. In the case of a high conductivity, a part of the in-phase measurement is generated by the conductivity (and the LIN approximation is not fulfilled) and in the case of a low conductivity the part of the out-of-phase measurement related to the magnetic susceptibility can be significant. The use of different frequencies has been proposed to correct both effects (Tabbagh 1986) and moreover it allowed the measurement of the quadrature part of the magnetic susceptibility (Benech 2000).

Studies on soil samples and TDEM measurements in the field have shown that the magnetic susceptibility is a complex quantity (Mullins and Tite 1973, Dabas and Skinner 1993). According to the dispersed single-domain grain theory, the imaginary part $\kappa_{q u}$ called the magnetic viscosity and the real part $\kappa_{p h}$ of the magnetic susceptibility are linked by the following relation:

$$
\frac{2}{\pi} \kappa_{q \alpha}=\frac{\partial \kappa_{\mathrm{qh}}(\omega)}{\partial \operatorname{Ln}(\omega)}
$$

It means that the in-phase magnetic susceptibility is a frequency dependent quantity and the out-ofphase magnetic susceptibility a non-dependant one. In common soils the quadrature part of the magnetic susceptibility is approximately $6 \%$ of the in-phase part. The knowledge of the magnetic susceptibility components is particularly interesting for determination of the size of the magnetic grains and is related to the nitrogen and carbon contents (Thiesson et al. 2012).

In the case of EMI Slingram measurement, the response generated by the imaginary part of the complex susceptibility adds algebraically to the one generated by the conductivity in the quadrature out-of-phase component of the signal. Nevertheless, the response of the quadrature part of the signal due to the conductivity increases with frequency, unlike the magnetic susceptibility. The use of different frequencies therefore allows separating the conductivity and the magnetic viscosity responses.

\section{Instrument and method}

To manage these multi-frequency measurements we used the GEM2 (Geophex, ltd). It is a broad-band instrument with a coil spacing of $1.66 \mathrm{~m}$ (Won et al. 1996). The two coils are Co-Planar allowing measurement in both HCP and VCP modes. One can choose 5 different frequencies between $300 \mathrm{~Hz}$ and $90 \mathrm{kHz}$, with an algebraic or a logarithmic progression. The instrument is not a simple dipoledipole one because it includes a bucking receiver coil at $1.035 \mathrm{~m}$ from the transmitter coil and the measured quantity is the difference between responses at the two receiver coils. Any interpretation must also use this difference and not the signal at the $1.66 \mathrm{~m}$ coil.

One first achieves a calibration of the instrument by comparing the result of a vertical electrical sounding and GEM2 measurements at two different heights. This allows relating the measurements' digits to true ppm ratios and to estimate the offsets of the instrument in quadrature. Then, at each measurement point, the apparent conductivity is determined from the difference between the quadrature responses at two different frequencies, which remove the quadrature responses of the magnetic susceptibility. This difference in ppm is converted in electrical conductivity by referring to the theoretical curve relating the conductivity (in $\mathrm{mS} / \mathrm{m}$ ) and the difference in the responses in ppm. Having the apparent conductivity value, it is then possible to calculate both in-phase and quadrature responses generated for each frequency and to remove them from the experimental responses. The 


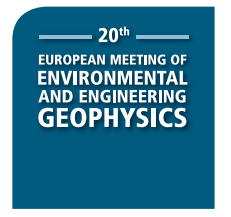

responses generated by the in-phase and out-of-phase components of the magnetic susceptibility were obtained for 5 frequencies. By referring to theoretical responses those are expressed in terms of the apparent complex magnetic susceptibility.
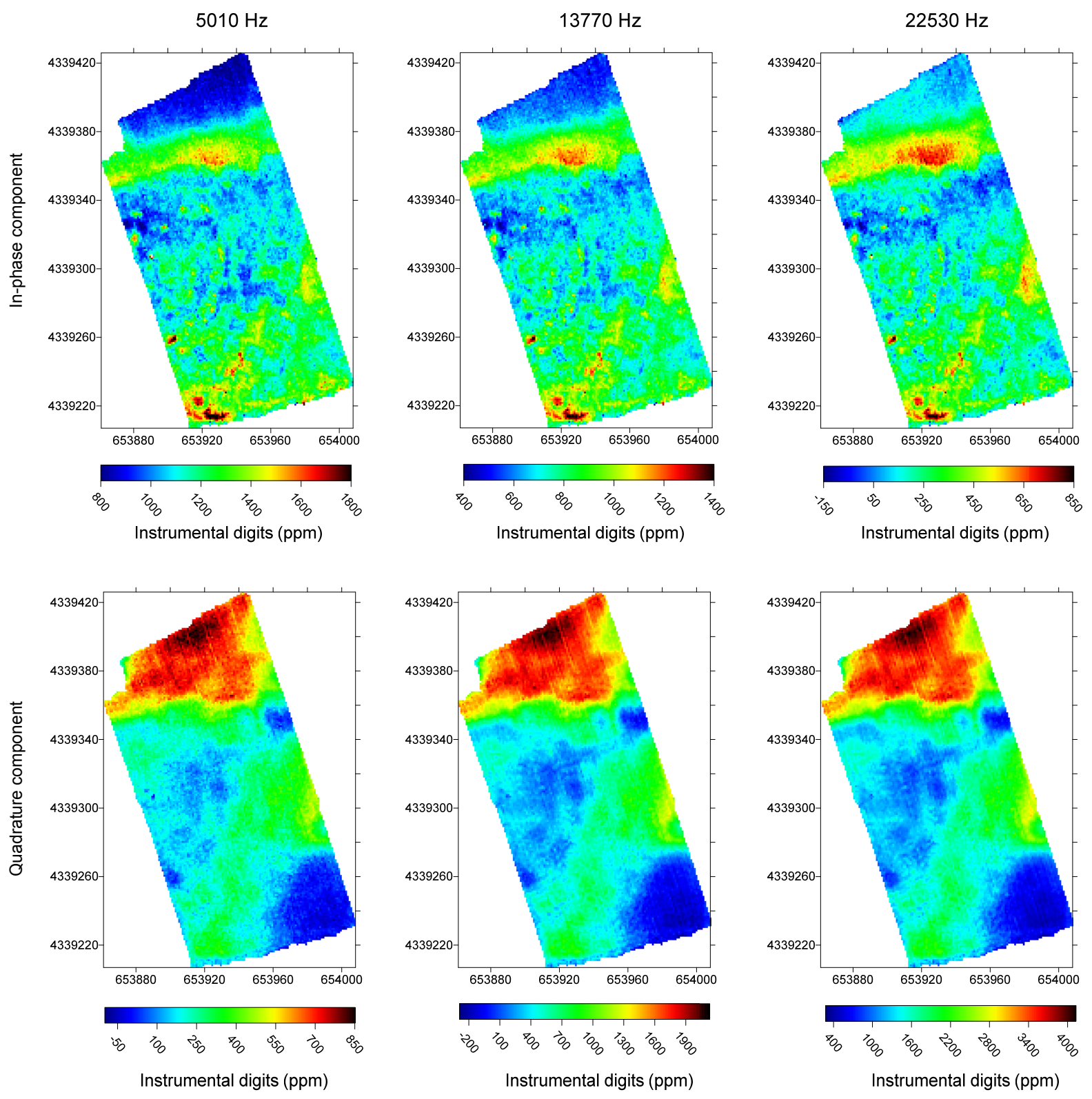

Figure 1 Map of GEM-2 raw data for $5010 \mathrm{~Hz}, 13770 \mathrm{~Hz}$ and $31290 \mathrm{~Hz}$ for in-phase (top) and quadrature out-of-phase component of the signal (bottom). For the quadrature the three different frequencies show a non-dependency on the frequency but for the in-phase signal we observe different offsets between the frequencies.

\section{Example}

The particular methodology was used on the archaeological site of Almiriotiki magoula, in Almyros, Thessaly (Greece) to map the spatial organization of the Neolithic settlement. Data were collected with a handle system and GPS-RTK positioning. The survey was carried out along parallel profiles one meter apart with a frequency of acquisition of $1 \mathrm{~Hz}$. We used 5 different measurement frequencies: $5010 \mathrm{~Hz}, 133700 \mathrm{~Hz}, 22530 \mathrm{~Hz}, 31290 \mathrm{~Hz}$ and $40050 \mathrm{~Hz}$. The instrument was carried at an altitude of $0.3 \mathrm{~m}$ from the ground. 


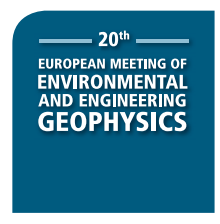

$5010 \mathrm{~Hz}$



$13770 \mathrm{~Hz}$

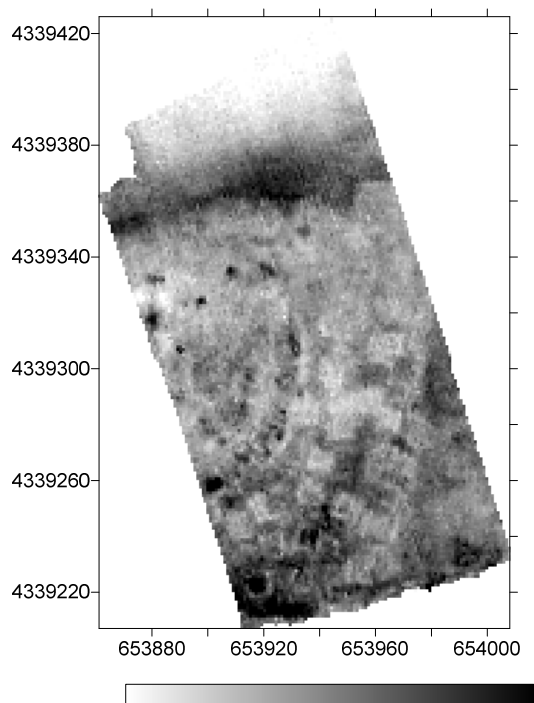

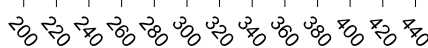

In-phase part of the magnetic susceptibility $\left(10^{-5} \mathrm{~S} . \mathrm{I}\right.$.)
$22530 \mathrm{~Hz}$

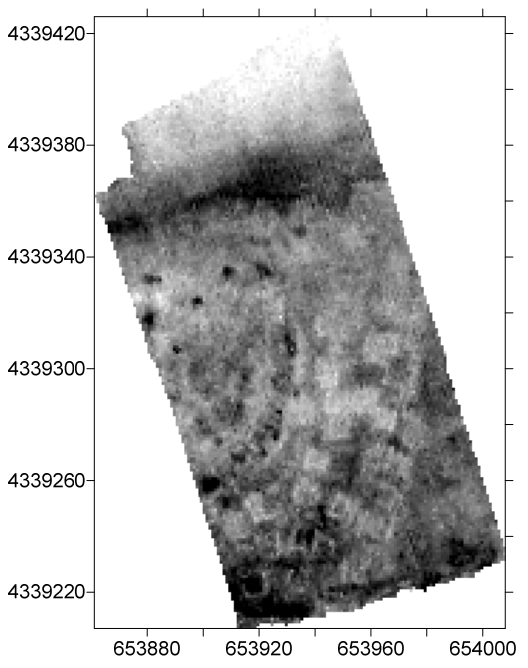

$5010 \mathrm{~Hz}$

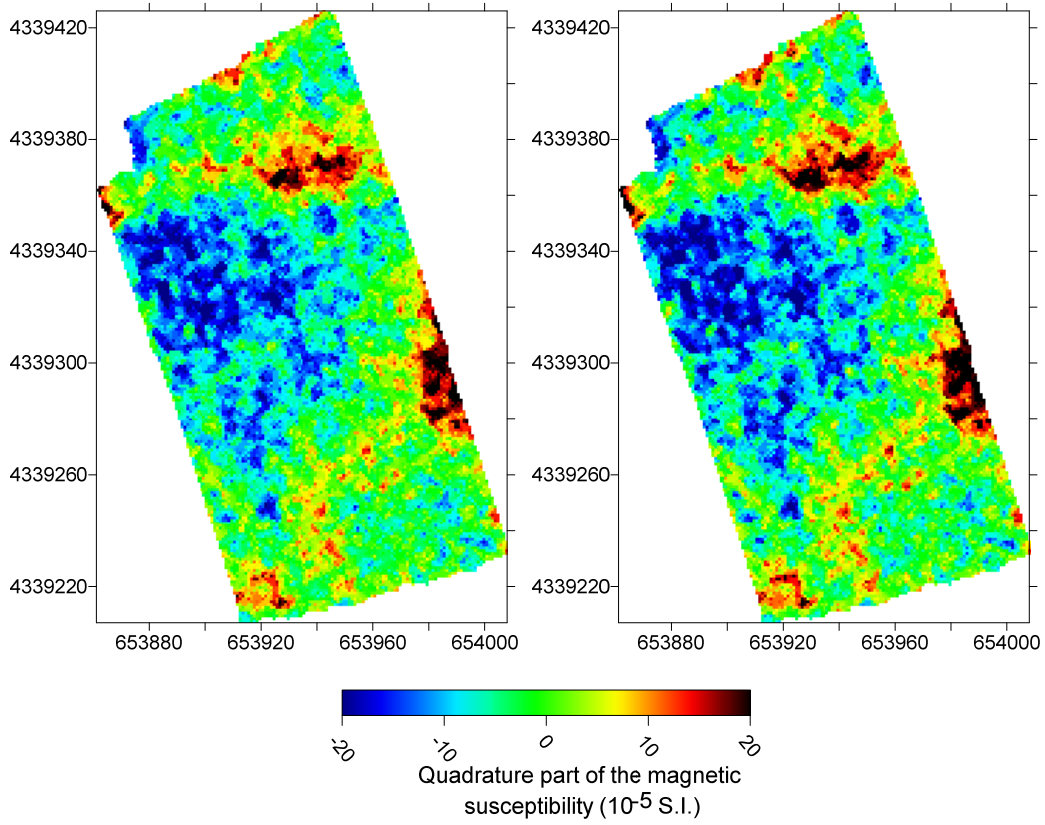

$13770 \mathrm{~Hz}$

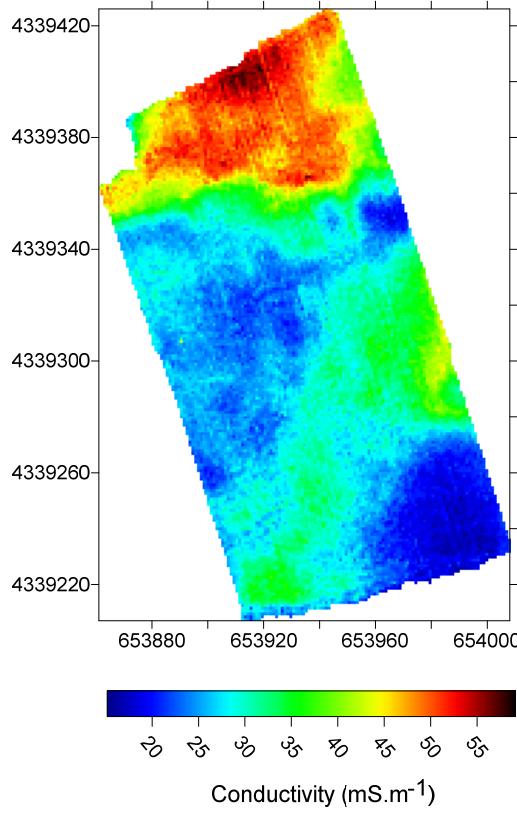

Figure 2 Map of the GEM-2 processed data: On the top, maps of the in-phase components of the magnetic susceptibility, for $5010 \mathrm{~Hz}, 13370 \mathrm{~Hz}$ and $31290 \mathrm{~Hz}$. On the bottom, maps of the quadrature components of the magnetic susceptibility for 5010 and $13770 \mathrm{~Hz}$ and of the conductivity (to the right). We observe an increase of the in phase susceptibility offset at the different frequencies. The quadrature components of the magnetic susceptibility, in accordance with the theory, are nondependent of the frequency.

On the raw data (Figure 1) we don't see any differences on the quadrature component of the signal for the different frequencies except the multiplicative effect of the frequency itself. For the in-phase component of the raw signal, some differences, especially to the north part of the map are related with the conductivity effects. Offsets for each frequency and each component suggest the requirement of a calibration. 
After processing (Figure 2), we obtain the conductivity, the in-phase magnetic susceptibility and the quadrature component of the magnetic susceptibility. The conductivity is high which explains its contribution in the in-phase components of the raw signal for the highest frequencies. For the in-phase magnetic susceptibility the three different frequencies show different zero adjustments partially induce by a poor calibration and by the complex variation of sign of the anomaly with depth in HCP (especially with contribution of the bucking coils). This particularity involves also a complex interpretation of the apparent susceptibility in HCP configuration; the shallow part of the soil may create a negative value of apparent magnetic susceptibility while the deeper strata can produce a positive one. Nevertheless, with some a priori on the context, it could be also informative about the depth of detected features. One observes that the relationship between quadrature and in-phase values is not far from the $6 \%$ value and that quadrature values don't change with the frequency according with the theory.

\section{Conclusion}

The used multi-frequency EM instrument allowed the measurement of the quadrature part of the magnetic susceptibility by the processing of data collected at different frequencies. Due to the information born by the complex magnetic susceptibility such measurements open new paths in soil properties' mapping that will be very interesting to study. The use of multi-frequency can also be improved, for instance by using frequencies close to $100 \mathrm{kHz}$, to determine the dielectric permittivity in this part of the low frequency range (Huang and Fraser 2002). Still, effects of polarization are probably not negligible and this property needs to be taken into account for a precise determination of the conductivity.

\section{Acknowledgement}

This work was performed in the framework of the IGEAN ("Innovative Geophysical Approaches for the study of Early Agricultural villages of Neolithic") project which is implemented under the "ARISTEIA" Action of the "OPERATIONAL PROGRAMME EDUCATION AND LIFELONG LEARNING" and is co-funded by the European Social Fund (ESF) and National Resources.

\section{References}

Benech, C. [2000] Interprétation conjointe de cartographies magnétique et électromagnétique des propriétés magnétiques des sols anthropisés. Thèse Université Pierre et Marie Curie, Paris.

Dabas, M. and Skinner, J.R. [1993] Time-domain magnetization for soils (VRM), experimental realtionship to quadrature susceptibility. Geophysics, 58(3), 326-333.

Huan, H. and Fraser, C.D. [2002] Dielectric permittivity and resistivity mapping using highfrequency, helicopter-borne EM data. Geophysics, 67(3), 727-738.

Mullins, C.E. and Tite, M.S. [1973] Magnetic viscosity, quadrature susceptibility, and frequency dependence of susceptibility in single-domain assemblies of magnetite and maghémite. Journal of Geophysical Research, 78(5), 804-809.

Tabbagh, A. [1986] Applications and advantages of the Slingram electromagnetic method for archaeological prospecting. Geophysics, 51(3), 576-584.

Thiesson, J., Boulone, L., Buvat, S., Jolivet, C., Ortolland, B. and Saby, N. [2012] Magnetic properties of the French Soil Monitoring Network: First Results. Near Surface Geoscience: $18^{\text {th }}$ European Meeting of Environmental and Engineering Geophysics, C13.

Won, I.J., Keiswetter, D.A., Fields, G.R.A. and Sutton, L.C. [1996] GEM-2: A new multifrequency electromagnetic sensor. Journal of Environmental and Engineering Geophysics, 1(2), 129-137. 